\title{
Effects of Composition, Structure Design, and Coating Thickness of Thermal Barrier Coatings on Thermal Barrier Performance
}

\author{
Sung-Hoon Jung, Soo-Hyeok Jeon, Je-Hyun Lee, Yeon-Gil Jung \\ School of Materials Science and Engineering, Changwon National University, Changwon 51140, Korea \\ *High Temperature Materials Research Group, Korea Institute of Materials Science, Changwon 51508, Korea \\ (Received August 9, 2016; Revised October 13, 2016; Accepted October 17, 2016)
}

\begin{abstract}
The effects of composition, structure design, and coating thickness of thermal barrier coating (TBC) on thermal barrier performance were investigated by measuring the temperature differences of TBC samples. TBCs with the thin and thick top coats were used for these studies, including TBCs with rare-earth (Gd, Yb, and La) compositions. The thermal barrier performance was enhanced with increasing the thickness of top coat even for thin TBCs, indicating that the thermal barrier performance was commensurate to the thickness of top coat. On the other hand, the bi-layered TBC, which was prepared with Yb-Gd-YSZ feedstock powder, with the buffer layer of high purity 8YSZ showed a better thermal barrier performance than that of regular purity 8YSZ. The interfaces in the bi-layered TBCs had a decisive effect on the thermal barrier performance, showing the performance enhanced with increasing numbers of interfaces. However, a new structural design and an additional process should be considered to reduce stress concentrations and to ensure interface stability, respectively, for improving thermal durability in the multilayered TBCs.
\end{abstract}

Key words : Thermal barrier coating, Thermal barrier performance, Thickness, Composition, Layered structure, Interface.

\section{Introduction}

$\mathrm{H}$ gh-temperature components in gas turbines for aviation and power generation are exposed to high-temperature flames, where Thermal Barrier Coatings (TBCs) are applied to prevent deterioration of parent metal due to thermal and mechanical stresses experienced by the high-temperature components. ${ }^{1,2}$ In general, the TBC system consists of MCrAlY ( $\mathrm{M}=\mathrm{Ni}$, Ni-Co and $\mathrm{Co}-\mathrm{Ni}$ )-based bond coat to confer oxidation-resistant and corrosion-resistant functions to the parent metal in high-temperature components, and extra adhesion of ceramic top coat to the parent metal, and of the top coat to confer thermal barrier performance. ${ }^{3)}$ The bond coat is formed by using Air Plasma Spray (APS), High Velocity Oxy-Fuel (HVOF), Vacuum Plasma Spray, etc. while the top coat is formed by APS method or Electron Beam Physical Vapor Deposition (EB-PVD) method. ${ }^{4-7)}$ The APS method used for the top coat is being mainly employed for high-temperature components of gas turbines for power generation due to economy and advantages for scale-up. While TBCs by EB-PVD method shows excellent thermal durability as compared with those by APS, it is mainly employed for high-temperature compo-

\footnotetext{
${ }^{\dagger}$ Corresponding author : Yeon-Gil Jung

E-mail : jungyg@changwon.ac.kr

Tel : +82-55-213-3712 Fax : +82-55-262-6486
}

nents in gas turbines for aviation due to limitations in equipment applicability for scale-up, high manufacturing costs, relatively high thermal conductivity. ${ }^{8)}$

In general, it is reported that the temperature experienced by the substrate can be reduced to about $150^{\circ} \mathrm{C}$ through incorporation of the TBC system. ${ }^{9)}$ Meanwhile, turbine inlet temperature is gradually being raised for the fuel efficiency and the output increase of gas turbines, and the stabilized zirconia doped with 7-8 wt\% $\mathrm{Y}_{2} \mathrm{O}_{3}$ (7-8YSZ) is exhibiting application limitations for high-temperature components in gas turbines with surface temperatures higher than $1200^{\circ} \mathrm{C}$ due to phase transition and sinterability at elevated temperatures. ${ }^{7,10)}$ Accordingly, studies on new materials for TBC are required which can overcome temperature accommodation limitations of superalloys used as a parent metal for high-temperature components through improvement of thermal barrier performance and which have phase stability as well as sintering resistance at high temperatures. ${ }^{11-14)}$ Recently, to overcome application limitations of YSZ materials, cooling design changes for high-temperature components in gas turbines together with studies on ceramic coating (top coat) materials of low thermal conductivity with addition of rare earth elements, such as Lanthanum (La), Ytterbium ( $\mathrm{Yb}$ ), Gadolinium (Gd), etc., are being actively conducted. ${ }^{7,15)}$ While thermal conductivity of the existing TBC material of $7-8 \mathrm{YSZ}$ is $2.1 \mathrm{~W}(\mathrm{~m} \cdot \mathrm{K})^{-1}$, it is reported to be $1.5 \mathrm{~W}(\mathrm{~m} \cdot \mathrm{K})^{-1}$ in the case of La-containing material for coating such as $\mathrm{La}_{2} \mathrm{Zr}_{2} \mathrm{O}_{7}$, and $0.8 \sim 1.2 \mathrm{~W}(\mathrm{~m} \cdot \mathrm{K})^{-1}$ 
in the case of materials for coatings which contain multiple rare earth elements such as Yb-Gd-YSZ. Here, it is reported that the added rare earth elements act as impurities, and reduce thermal conductivity by increasing phonon scattering effects due to mass difference caused by substitution. ${ }^{7,16)}$ Also, pyrocholore oxide materials with $\mathrm{La}, \mathrm{Gd}, \mathrm{Yb}$, etc. have excellent thermal characteristics. While TBC materials with addition of rare earth elements are reported to show excellent phase stability and sintering resistance at high temperatures, ${ }^{7,17)}$ they induce delamination of the top coat by forming high thermal and residual stresses at the interface due to the relatively low coefficient of thermal expansion, CTE, (Yb-Gd-YSZ: $9 \sim 10 \times 10^{-6} \mathrm{~K}^{-1}, \mathrm{La}_{2} \mathrm{Zr}_{2} \mathrm{O}_{7}: 9.1 \sim 9.7 \times$ $10^{-6} \mathrm{~K}^{-1}$, and 8YSZ: $10.5 \sim 11.5 \times 10^{-6} \mathrm{~K}^{-1}$ ) compared with the 7-8YSZ giving rise to a difference in CTE from that of the bond coat (NiCrAlY bond coat: $15.0 \times 10^{-6} \mathrm{~K}^{-1}$ at $\left.1000^{\circ} \mathrm{C}\right){ }^{17-19)}$

In addition to the thermal characteristics, the low thermal conductivity materials containing rare earth elements cause the results where thermal durability of TBCs is degraded due to low mechanical characteristics (Yb-Gd-YSZ fracture toughness: $\sim 1.25 \mathrm{MPa} \times \mathrm{m}^{1 / 2}, \mathrm{La}_{2} \mathrm{Zr}_{2} \mathrm{O}_{7}$ fracture toughness: $\sim 1.1 \mathrm{MPa} \cdot \mathrm{m}^{1 / 2}$ ) compared with the 7-8YSZ (8YSZ fracture toughness: $\left.\sim 2.23 \mathrm{MPa} \times \mathrm{m}^{1 / 2}\right) .{ }^{17,20)}$ Also, in the case of coating layer with addition of $\mathrm{Gd}$, failure of top coat occurs easily due to the characteristics difference from those of TGO layer during operation. ${ }^{21)}$ Thus, to secure applicability of the low thermal conductivity materials containing rare earth elements, i.e. to supplement disadvantages in thermal and mechanical characteristics, the studies on incorporation of buffer layer between the bond and top coats or application to starting powder of mixing with the 7-8YSZ are being continuously performed. ${ }^{22,23)}$ Meanwhile, since composition, thickness, structure, etc. in TBC system have large effects on the thermal barrier performance, thermal barrier performance as a function of composition, thickness, structure, etc. in TBC system needs to be considered to secure applicability of the low thermal conductivity materials. However, while the applicability of the low thermal conductivity materials is currently being studied according to microstructure design related to the control of process variables, specific measures for consideration of thermal barrier performance have not been presented. ${ }^{2)}$

Therefore, in the present study, temperatures of the top coat surface and of the bottom face of substrate were measured for the TBC systems prepared by varying composition of the starting material and thickness of the coating layer to comparatively evaluate their thermal barrier performance. Through this procedure, effectiveness of structures for application of the low thermal conductivity materials together with mechanism for manifestation of thermal barrier performance has been considered.

\section{Experimental Procedure}

\subsection{Preparation of starting powders and specimens}

Bond coats were formed by using commercial coating pow- der of AMDRY 9624 and AMDRY962 (Sulzer Metco Holding $\mathrm{AG}$, average weight ratio composition: $\mathrm{Ni}-22 \mathrm{Cr}-10 \mathrm{Al}-1.0 \mathrm{Y}$, average particle sizes: $45 \sim 74 \mu \mathrm{m}$ (AMDRY 9624) and $53 \sim$ 106 $\mu \mathrm{m}$ (AMDRY 962)), AMDRY 9951 (Sulzer Metco Holding $\mathrm{AG}$, average weight ratio composition: $\mathrm{Co}-32 \mathrm{Ni}-21 \mathrm{Cr}-8 \mathrm{Al}-$ 0.5Y, average particle size: $5 \sim 37 \mu \mathrm{m}$ ), and AMDRY 997 (Sulzer Metco Holding AG, average weight ratio composition: Ni-23Co-21Cr-9Al-0.6Y,average particle size: 5 $38 \mu \mathrm{m})$. In formation of the bond coat, AMDRY 9624 and AMDRY 997 were applied to HVOF (Diamond Jet-2600 DJM, Sulzer Metco Holding AG, Switzerland) method, while AMDRY 962 was applied to APS (9MB, Sulzer Metco Holding AG, Switzerland) method. Top coats were formed by using APS method for the commercial powder of METCO 204 C-NS of general purity, and METCO 204C-XCL of high purity (METCO $204 \mathrm{C}-\mathrm{NS}: 8.0 \mathrm{Y}_{2} \mathrm{O}_{3}-0.7 \mathrm{SiO}_{2}-0.2 \mathrm{TiO}_{2}-0.2 \mathrm{Al}_{2}$ $\mathrm{O}_{3}-0.2 \mathrm{Fe}_{2} \mathrm{O}_{3}$ doped in $\mathrm{ZrO}_{2}$ and METCO 204 C-XCL: $8.0 \mathrm{Y}_{2} \mathrm{O}_{3}-0.05 \mathrm{SiO}_{2}-0.05 \mathrm{TiO}_{2}-0.05 \mathrm{Al}_{2} \mathrm{O}_{3}-0.05 \mathrm{Fe}_{2} \mathrm{O}_{3}$ doped in $\mathrm{ZrO}_{2}$, Sulzer Metco Holding AG, Switzerland, average particle size: 45 140 $\mu \mathrm{m}$, D50: $68 \sim 77 \mu \mathrm{m}$ ), METCO 206A with addition of rare earth elements such as $\mathrm{Y}, \mathrm{Yb}$, and Gd (Sulzer Metco Holding AG, Switzerland, $\mathrm{ZrO}_{2}$ with addition of $9.5 \mathrm{Y}_{2} \mathrm{O}_{3}-5.6 \mathrm{Yb}_{2} \mathrm{O}_{3}-5.2 \mathrm{Gd}_{2} \mathrm{O}_{3}$, average particle size: $45 \sim 125 \mu \mathrm{m}$ ), and commercial $\mathrm{La}_{2} \mathrm{Zr}_{2} \mathrm{O}_{7}$ powder (LZO, LAO-109-1, Praxair Surface Technologies, Indianapolis, IN). In addition, LZO powder and $204 \mathrm{C}-\mathrm{NS}$ powder were mixed and employed as a starting powder.

To evaluate the thermal barrier performance as a function of thickness, the total thicknesses of TBC systems were designed to be 250 and $1000 \mu \mathrm{m}$, and the thickness ratio between the top and bond coats was varied when the total thickness of TBC system was $250 \mu \mathrm{m}$. This was aimed at considering the effects of top coat thickness on thermal barrier performance for the same coating thickness and securing an optimum ratio in coating thickness. Accordingly, the thickness ratios between the top and bond coats for the structure were designed to be $150: 100$ and $200: 50$ for the thin TBC system, while the ratio was designed to be 850 : 150 for the thick TBC system. Detailed structural design is shown in Fig. 1. Namely, in the thin TBC system, the bond coats had compositions varied and were formed by HVOF method to the thicknesses of 100 and $50 \mu \mathrm{m}$, respectively, while the top coats were formed on each bond coat using 8YSZ by APS method to the thicknesses of 150 and $200 \mu \mathrm{m}$, respectively. In the thick TBC system, Ni-based bond coat was formed by APS method to the thickness of $150 \mu \mathrm{m}$, while the top coat was formed using 8YSZ by APS method to the thickness of $850 \mu \mathrm{m}$. In addition, the top coat with a bi-layer structure was designed to evaluate thermal barrier performance as functions of composition of bond coat and purity of buffer layer, which is shown in Fig. 2. In the bilayer structure, the buffer layer was formed using a general purity (METCO 204 C-NS) and a high purity (METCO 204 C-XCL) by APS method to the thickness around $60 \mu \mathrm{m}$, and the top coat was formed using a low thermal conductivity powder of Yb-Gd-YSZ by APS method to the thickness 

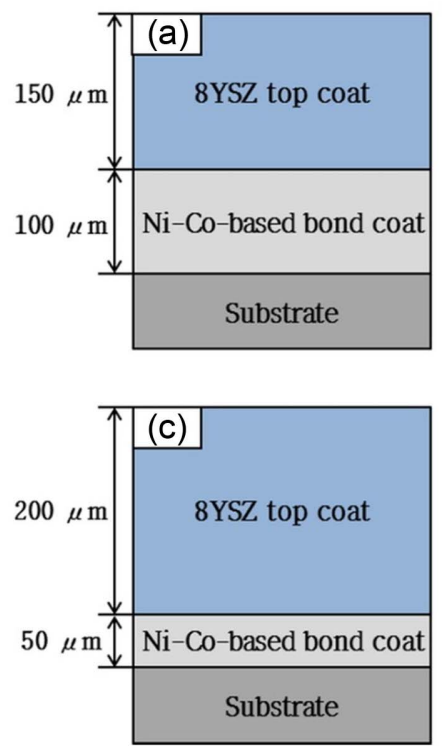
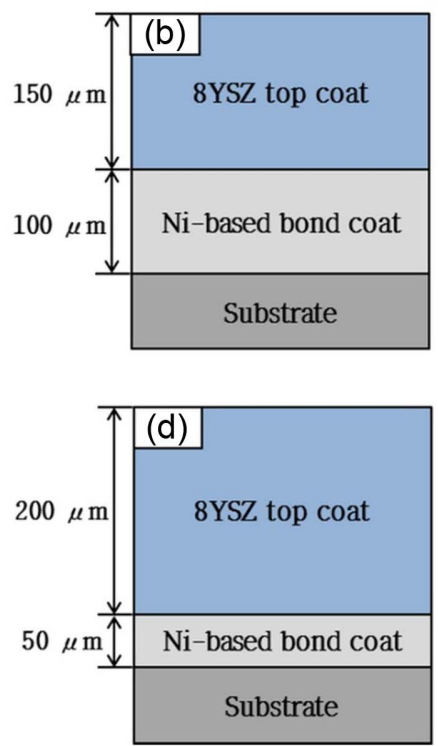

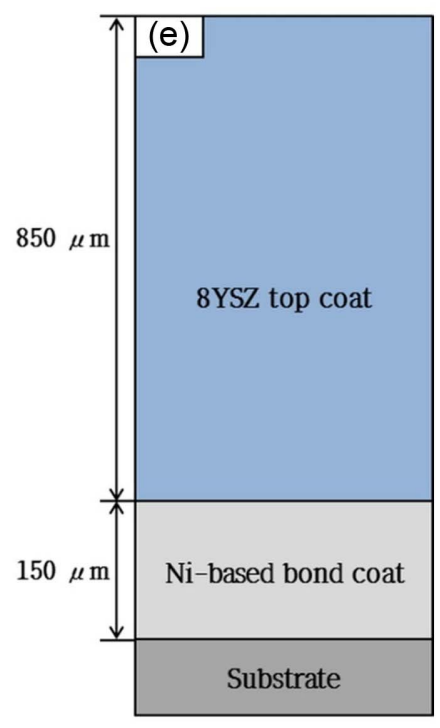

Fig. 1. Schematic diagram of structural design in thin and thick TBCs.

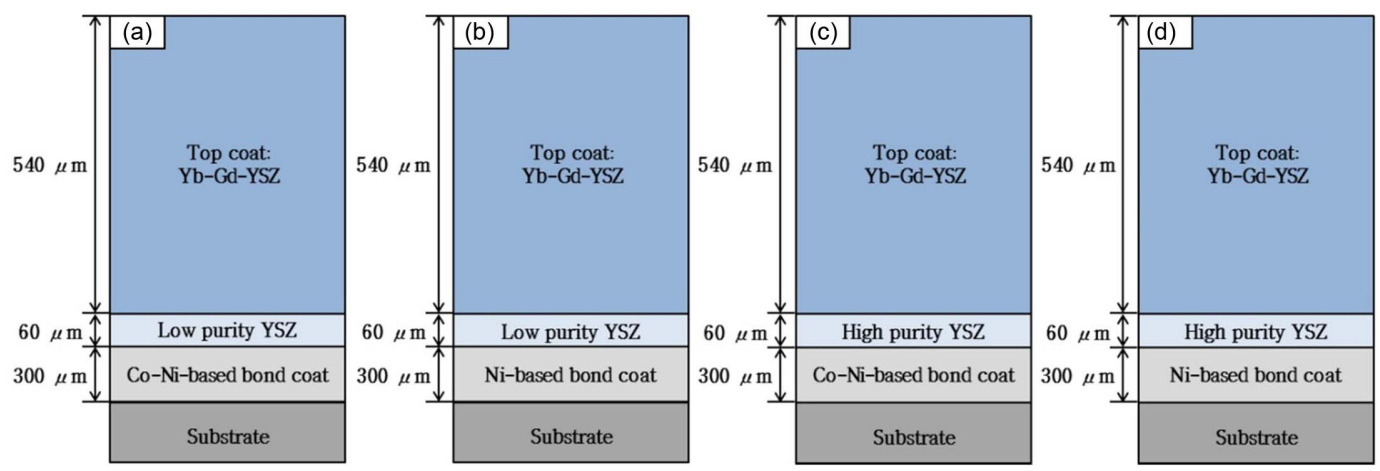

Fig. 2. Schematic diagram of structural design in layered TBCs using the Yb-Gd-YSZ and YSZ feedstock powders.

around $540 \mu \mathrm{m}$. The bond coats in TBC systems of the bilayer structure were formed using AMDRY 9951 and AMDRY 997, respectively, by HVOF to the thickness of 300 $\mu \mathrm{m}$. Also, for evaluation of thermal barrier performance as functions of structure and composition in the top coat, the TBCs were designed as functions of the composition and number of the buffer layer as well as the composition and number of the top coat, which is shown in Fig. 3. Here, the bond coat was formed using AMDRY 962 by APS method to the thickness of $150 \mu \mathrm{m}$, and 8YSZ alone or LZO and 8YSZ mixed in $25: 75$ vol\% was applied to the buffer layer. Meanwhile, top coats in the multilayer structure were formed using LZO and 8YSZ mixed in 50:50 vol\% and $25: 75 \mathrm{vol} \%$ as well as 8YSZ alone. Total thickness of the top coat was varied as shown in Fig. 3, and correlation between the thickness and number of coating layer was discussed.

\subsection{Characteristics evaluation}

To affirm the status of cracking inside coating layer, cracking and delamination at interfaces which can be included upon formation of TBC system, microstructure was observed as functions of thickness, composition, and incorporation status of the buffer layer. The specimens were mounted with a fluid epoxy resin, polished using silicon carbide paper, then final polishing using $3 \mu \mathrm{m}$ and $1 \mu \mathrm{m}$ diamond pastes. The cross-sectional microstructure of TBC specimens was observed using a scanning electron microscope (SEM, JEOL Model JSM-5610, Japan). Also, for differentiation of interfaces as resulting from incorporation of the buffer layer and conversion to multilayers, a composition analysis was conducted for each top coat by using an energy dispersive spectrometer (EDS, Oxford Instruments, Oxford, UK).

To evaluate thermal barrier performance as functions of thickness, composition, and incorporation status of the buffer layer in TBC system, Jet Engine Thermal Shock (JETS) test was employed, and the equipment used for evaluation of thermal barrier performance is shown in Fig. 4. In JETS test, the surface of top coat was heated for 20 seconds using flame at $1400^{\circ} \mathrm{C}$ with a mixture of LPG and oxygen, and then cooling for 20 seconds using nitrogen gas was conducted, which constituted one cycle, until 2000 cycles. JETS 

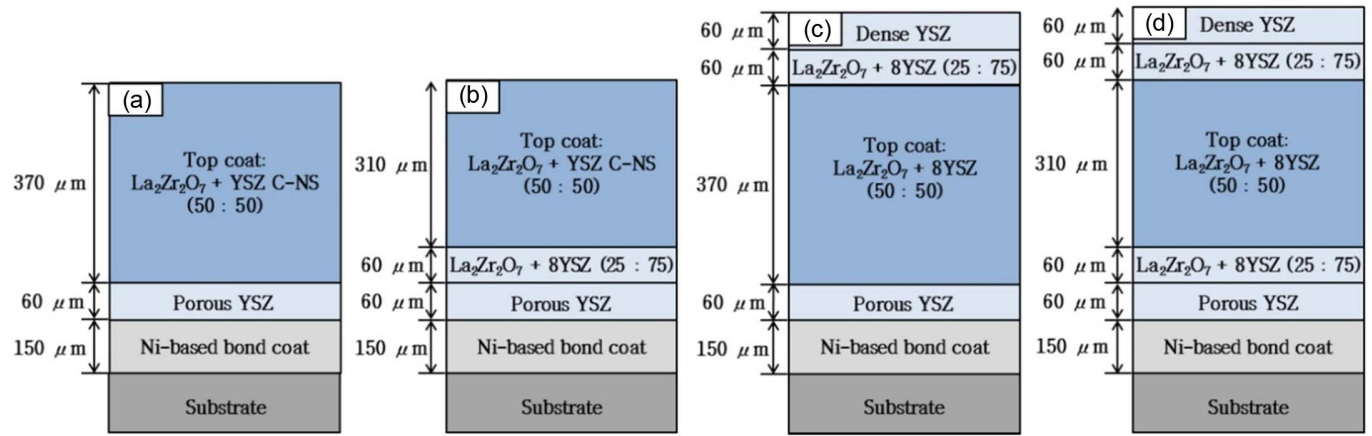

Fig. 3. Schematic diagram of structural design in layered TBCs using the blended feedstock powder of $\mathrm{La}_{2} \mathrm{Zr}_{2} \mathrm{O}_{7}$ and $\mathrm{YSZ}$, and the YSZ feedstock powder.

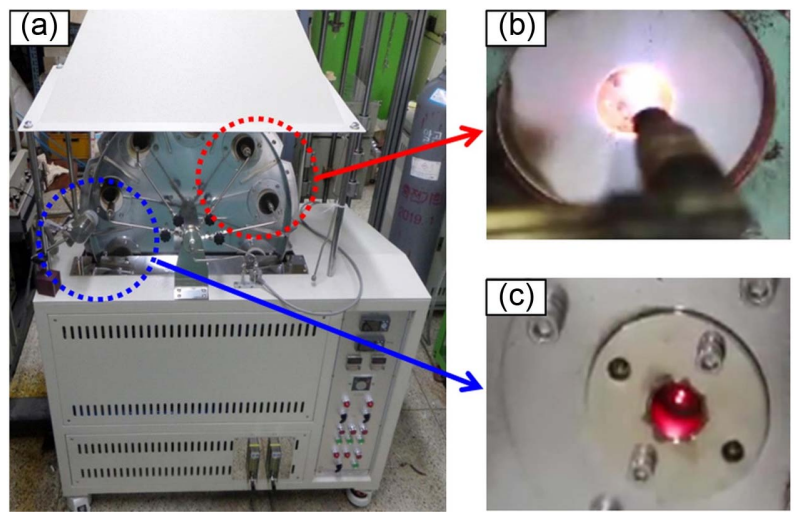

Fig. 4. Photos of test apparatus: (a) jet engine thermal shock (JETS) apparatus, (b) heating part, and (c) cooling part.

test is a universally applied method by OEM (Original Equipment Manufacturing) industry to evaluate thermal stability of TBCs, which can evaluate interface stability under drastic temperature changes. Also, in JETS test, the flame was prevented from being applied to other parts of the specimen except for the top coat surface by wrapping surroundings of the specimen with a ceramic holder. Pyrometer (Infrared thermometer, Wavelength : $3.9 \mu \mathrm{m}$, CTlaser MT, Optris, Germany) was installed on the surface of top coat and the back face of substrate, and temperatures were measured by using the pyrometer for 20 seconds during which the flame was applied, with calibration of the pyrometer being conducted by using a thermocouple whenever composition, thickness, and structure was changed. The surface temperature of TBC was increased to about $1000^{\circ} \mathrm{C}$ by heating for 20 seconds, at which time the temperature on the back face of substrate reached a range of $560 \sim 610^{\circ} \mathrm{C}$. Meanwhile, the surface temperature of the top coat and the back face temperature of substrate cooled down to about $550^{\circ} \mathrm{C}$ and about $350^{\circ} \mathrm{C}$, respedively, during cooling by nitrogen gas for 20 seconds. Thermal barrier performance of TBC was evaluated by measuring temperatures for the total of 4 sections after setting up according to the number of cycles (Section 1:0 $\sim 50$ cycles, Section 2:500 1000 cycles, Sec- tion $3: 1000 \sim 1500$ cycles, and Section 4: $1500 \sim 200$ 0cycles). To evaluate thermal barrier performance as a function of thickness, temperature difference between the surface of top coat and the back face of substrate was affirmed first for the 4 types of TBC systems having a thin thickness, and a comparison was made with the thick TBC system after selecting 1 type with the excellent thermal barrier performance. Thermal barrier performance was also compared and considered for composition, incorporation status of the buffer layer, and conversion to multilayers in TBC system by the same method of measuring temperatures of the surface of each top coat and the back face of substrate.

\section{Results and Discussion}

\subsection{Thermal barrier performance as a function of coating thickness}

The cross-sectional microstructures of TBC systems formed in accordance with Fig. 1 are shown in Fig. 5, which was designed by varying thickness ratio in the bond and top coats and thickness in the top coat. In the thin TBC system of Figs. 5(a) - (d), the top coat thicknesses were formed to be $110 \sim 154$ (Figs. 5(a) and 5(b)) and $176 \sim 185 \mu \mathrm{m}$ (Figs. 5(c) and $5(\mathrm{~d})$ ), respectively, while those of the bond coat were formed to be $76 \sim 56$ and $31 \sim 57 \mu \mathrm{m}$, respectively, with the thicknesses being formed to be somewhat thinner than the designed values. Meanwhile, in the thick TBC system of Fig. 5(e), the thicknesses of the bond and top coats were formed to be about $131 \sim 145$ and $820 \sim 878 \mu \mathrm{m}$, respectively. In TBC systems, no cracking and delamination at interfaces between coating layers were affirmed irrespective of the thickness ratio between coating layers (thickness ratio between the bond and top coats) and the thickness, with clear differences of thickness being affirmed in the microstructures. In the top coat, inherent defects such as pore, splat boundary, and unmelted particles, etc. appearing in the microstructures formed by APS method were observed, and relatively porous microstructures were observed in the top coat of all specimens.

Thermal barrier performance, i.e. for temperature difference, evaluated for the TBC systems having cross-sectional 

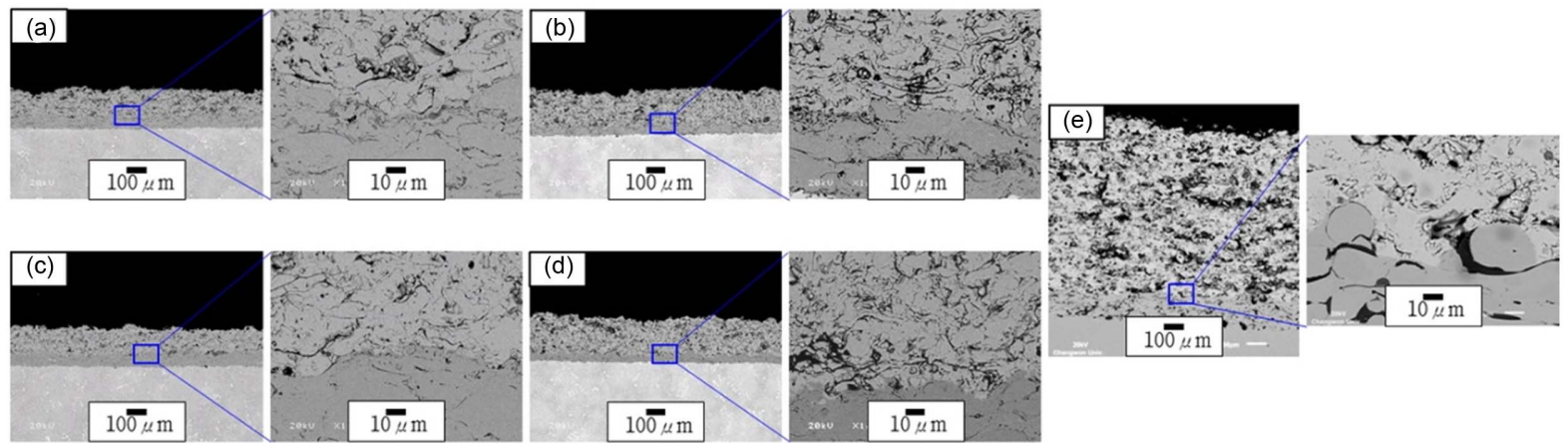

Fig. 5. Cross-sectional microstructures of as-coated TBCs prepared with the structural design shown in Fig. 1 and its high magnified microstructures at the interfaces.

Table 1. Summary of the Numbers of Cycle-to-failure and its Status after JETS Tests for the Thin and Thick TBCs, as Shown in Fig. 1.

\begin{tabular}{ccc}
\hline Type & Cycle & $\begin{array}{c}\text { Thermal barrier } \\
\text { performance }\end{array}$ \\
\hline Specimen a & $\begin{array}{c}2000 \text { cycles } \\
\text { Sound condition }\end{array}$ & $110 \sim 132^{\circ} \mathrm{C}$ \\
\hline Specimen b & $\begin{array}{c}2000 \text { cycles } \\
\text { Sound condition }\end{array}$ & $115 \sim 155^{\circ} \mathrm{C}$ \\
\hline Specimen c & $\begin{array}{c}2000 \text { cycles } \\
\text { Sound condition }\end{array}$ & $132 \sim 179^{\circ} \mathrm{C}$ \\
\hline Specimen d & $\begin{array}{c}2000 \text { cycles } \\
\text { Sound condition }\end{array}$ & $119 \sim 193^{\circ} \mathrm{C}$ \\
\hline Specimen e & $\begin{array}{c}2000 \text { cycles } \\
\text { Sound condition }\end{array}$ & $248 \sim 699^{\circ} \mathrm{C}$ \\
\hline
\end{tabular}
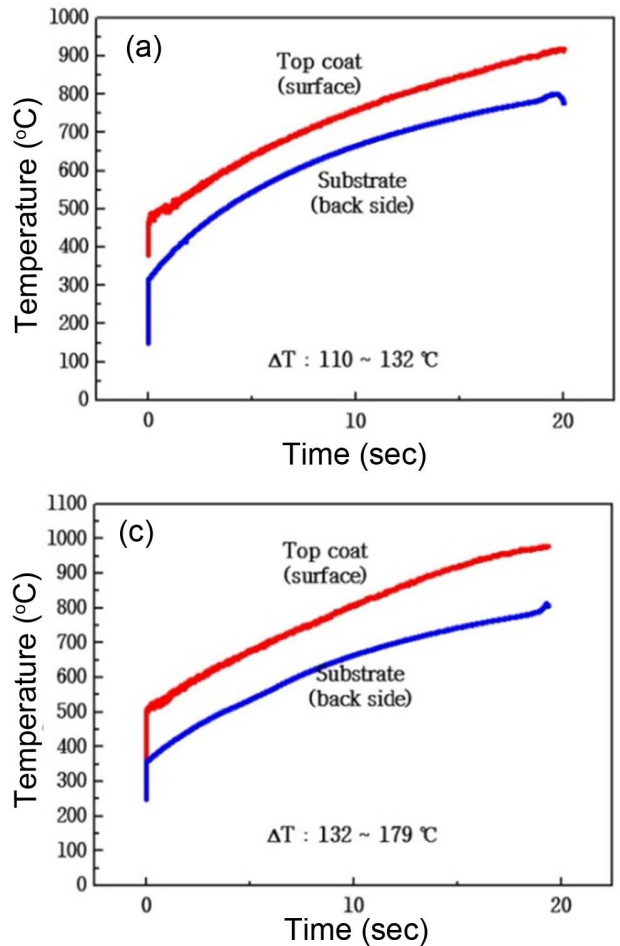

microstructure of Fig. 5 is shown in Table 1 and Figs. 6 and 7. For both the thin and thick TBC systems, the temperature difference was measured in Section 3 (1000 1500 cycles), and the temperature differences as a function of thickness ratio between the bond and top coats were measured and shown in Fig. 6 for the relatively thin TBC systems. In the case of TBC systems where the bond and top coats were designed and formed to be 150 and $100 \mu \mathrm{m}$, respectively, the TBC system having Ni-Co-based bond coat showed a thermal barrier performance (temperature difference) of $110 \sim$ $132^{\circ} \mathrm{C}$, and the TBC system having Ni-based bond coat a thermal barrier performance of $115 \sim 155^{\circ} \mathrm{C}$ as shown in Figs. 6(a) and 6(b), respectively. Meanwhile, in the case of TBC systems where the bond and top coats were formed to be 200 and $50 \mu \mathrm{m}$, respectively, the TBC system having Ni-
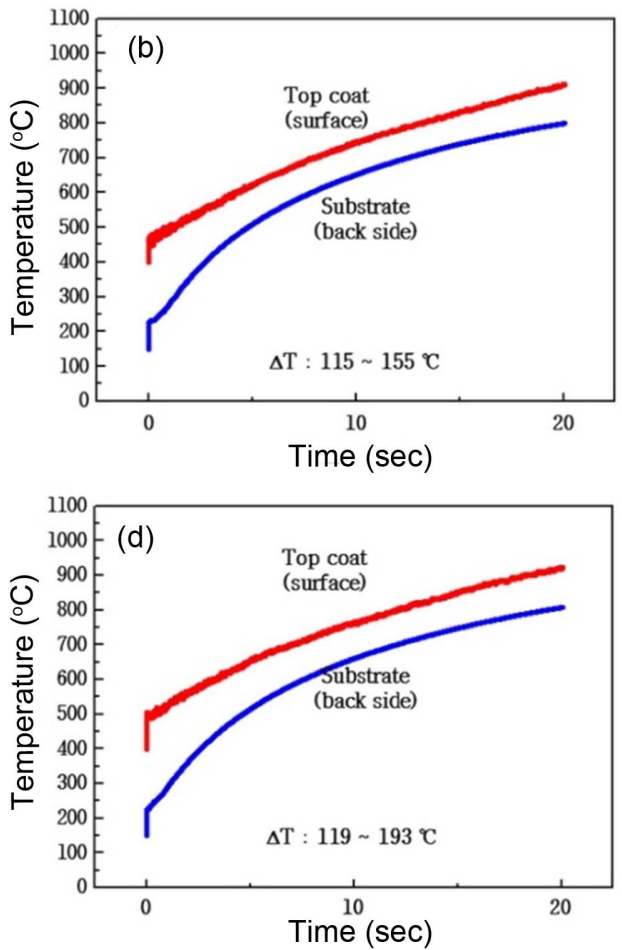

Fig. 6. Temperature differences of thin TBCs prepared with bond coat composition and thickness ratio in the bond and top coats: (a) $3: 2$ ratio in YSZ top coat and Ni-Co-based bond coat, (b) $3: 2$ ratio in YSZ top coat and Ni-based bond coat, (c) $4: 1$ ratio in YSZ top coat and Ni-Co-based bond coat, and (d) 4:1 ratio in YSZ top coat and Ni-based bond coat. 

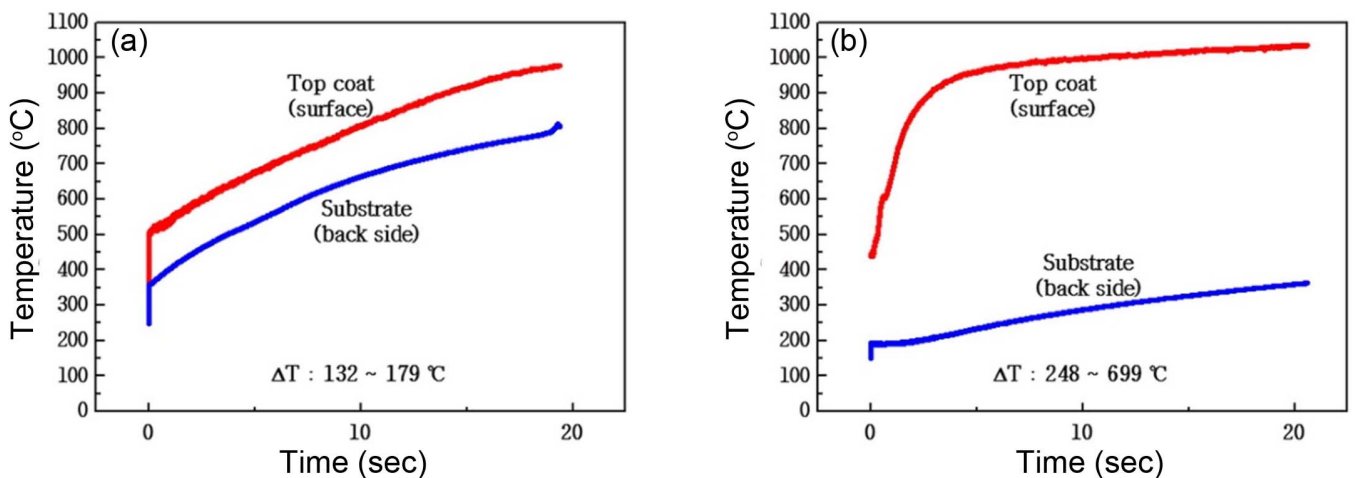

Fig. 7. Temperature differences of thin and thick TBCs: (a) thin TBC system of 8YSZ top coat and Ni-Co-based bond coat with 200 and $50 \mu \mathrm{m}$, respectively, and (b) thick TBC system of 8YSZ top coat and Ni-based bond coat with 850 and $150 \mu \mathrm{m}$, respectively.
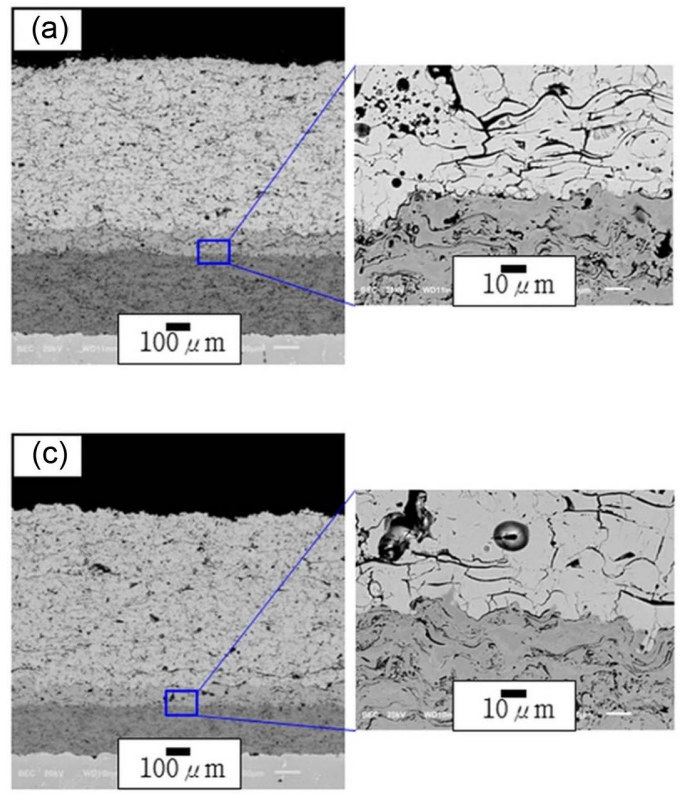
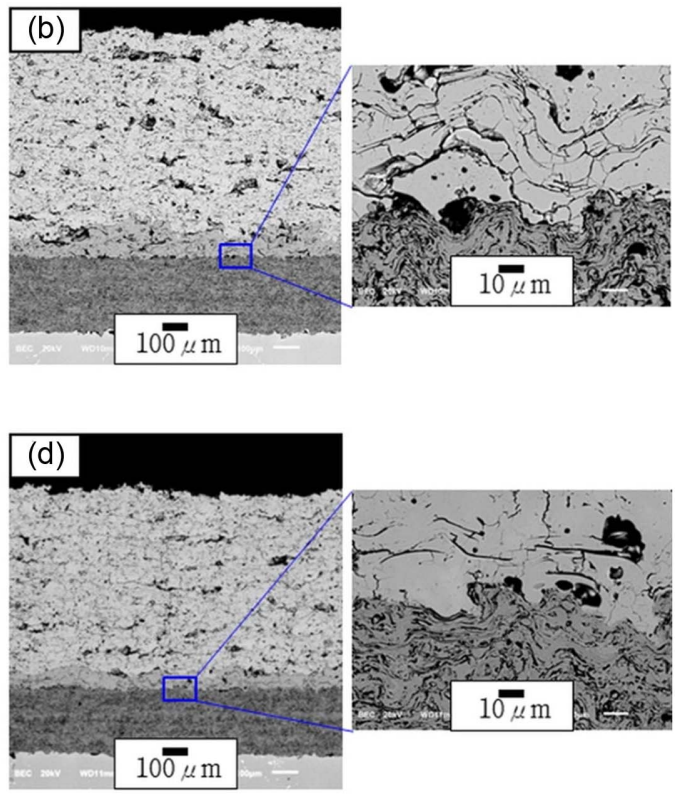

Fig. 8. Cross-sectional microstructures of as-coated TBCs prepared with the structural design shown in Fig. 2 and its high magnified microstructures at the interfaces.

Co-based bond coat showed a temperature difference of $132 \sim 179^{\circ} \mathrm{C}$, and the TBC system having Ni-based bond coat a temperature difference of $119 \sim 193^{\circ} \mathrm{C}$ as shown in Figs. 6(c) and 6(d), respectively. Based on such results, thermal barrier performance could also be affirmed to be improved as the thickness of the top cost increases in relatively thin TBC system. Also, composition of the bond coat could be seen to have no effects on the temperature difference, i.e. thermal barrier performance. The results of comparative consideration for thermal barrier performance are shown in Fig. 7 as a function of the thickness of TBC system, and compared with the results of Fig. 6(c) as the case showing the largest temperature difference in Fig. 6 for understanding improvement in thermal barrier performance in the thick TBC system. Temperature differences in the thick TBC were $248 \sim 699^{\circ} \mathrm{C}$, showing excellent thermal barrier performance compared with the thin TBC system
(Fig. 7(b)). This is a result in agreement with the report that the temperatures experienced by high-temperature components for gas turbines were lowered by $4 \sim 9^{\circ} \mathrm{C}$ whenever the coating thicknes was increased by $25 \mathrm{~mm} .{ }^{24)}$ In the present study, similar results were also observed in Section 1, Section 2, and Section 3 not shown here, and no delamination or fracture was observed in the specimens even after 2000 cycles.

\subsection{Thermal barrier performance in application of low thermal conductivity material and incor- poration of buffer layer}

The cross-sectional microstructures of TBC systems formed in accordance with Fig. 2 are shown in Fig. 8, which was designed with incorporation of the 8YSZ material as the buffer layer to supplement the low CTE and the low mechanical properties of the low thermal conductivity mate- 
rials. The thickness of the top coat was formed to be $578 \sim$ $761 \mu \mathrm{m}$, and that of bond coat $185 \sim 318 \mu \mathrm{m}$, while the specimen c (Fig. 8(c)) was formed to be relatively thick. The buffer layer was $67 \sim 119 \mu \mathrm{m}$ thick and formed to be thicker than the designed thickness as a whole. Meanwhile, since the buffer layer thicknesses were designed and formed to allow improvement to be produced in the same range as fracture or delamination in TBC system generally occurred around $100 \mu \mathrm{m}$ from the interface between the bond and top coats. ${ }^{25,26)}$ As mentioned earlier, only inherent defects visible in the microstructures formed by APS method were observed in the top coat, and no cracking and delamination were observed at the interface in the bond and top coats, and between the buffer layers.

The results of temperature differences at Section 1 (0 500 cycles) for all 4 types of specimens for the TBC systems prepared by application of Yb-Gd-YSZ starting powder and incorporation of 8YSZ buffer layer, which were designed to secure thermal durability, are shown in Table 2 and Fig. 9. First, when the buffer layer was incorporated, the larger temperature difference, i.e. the more excellent thermal barrier performance was manifested, the higher the purity of buffer layer (purity of starting powder). When the starting powders of general purity were used, the TBC systems with the Ni-Co-based and Ni-based bond coat compositions showed temperature differences of $284 \sim 369^{\circ} \mathrm{C}$ (Fig. 9(a)) and $380 \sim 435^{\circ} \mathrm{C}$ (Fig, 9(b)), respectively. When the buffer layer was formed using a starting powder of high purity,
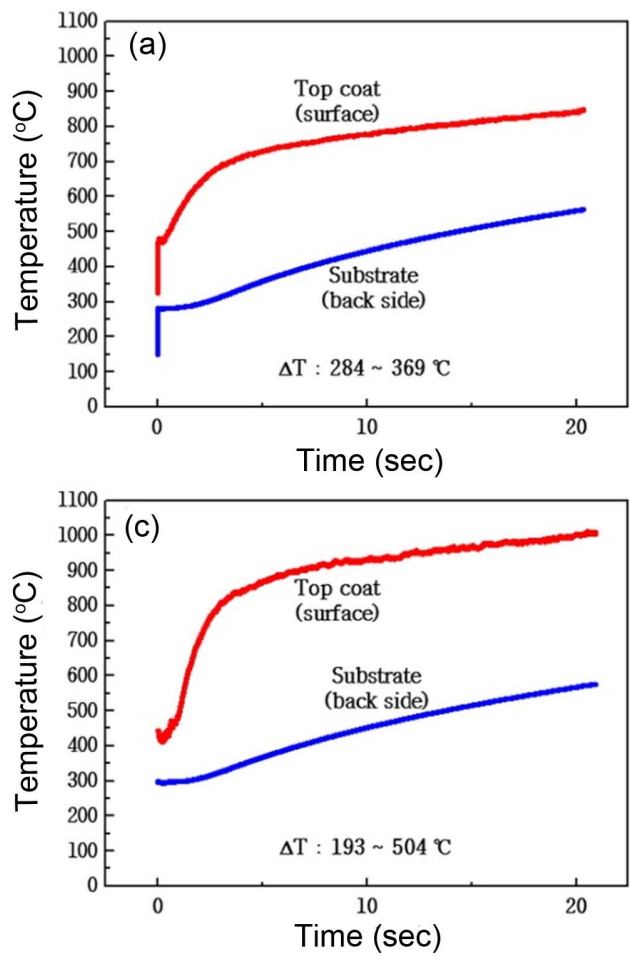

the TBC systems with the Ni-Co-based and Ni-based bond coat compositions showed temperature differences of $193 \sim 504^{\circ} \mathrm{C}$ (Fig. 9(c)) and $276 \sim 632^{\circ} \mathrm{C}$ (Fig. 9(d)), respectively. Also, temperature differences were measured with composition of the bond coat, and excellent thermal barrier performance was manifested in the TBC system with application of Ni-based bond coat (Figs. 9(b) and 9(d)), unlike Fig. 6 for the thin TBC system. Such large temperature differences are considered attributable to the improvement in thermal barrier performance due to Yb-Gd-YSZ coating layer of low thermal conductivity and the effect of thermal dispersion at interfaces due to formation of additional interfaces through incorporation of the buffer layer. Consequently, manifestation of thermal barrier performance can

Table 2. Summary of the Numbers of Cycle-to-failure and its Status after JETS Tests for TBCs with Yb-Gd-YSZ Top Coat and Buffer Layer, as Shown in Fig. 2.

\begin{tabular}{ccc}
\hline Type & Cycle & $\begin{array}{c}\text { Thermal barrier } \\
\text { performance }\end{array}$ \\
\hline Specimen a & $\begin{array}{c}720 \text { cycles } \\
\text { Delamination }\end{array}$ & $284 \sim 369^{\circ} \mathrm{C}$ \\
\hline Specimen b & $\begin{array}{c}1127 \text { cycles } \\
\text { Delamination }\end{array}$ & $380 \sim 435^{\circ} \mathrm{C}$ \\
\hline Specimen c & $\begin{array}{c}218 \text { cycles } \\
\text { Delamination }\end{array}$ & $193 \sim 504^{\circ} \mathrm{C}$ \\
\hline Specimen d & $\begin{array}{c}2000 \text { cycles } \\
\text { Sound condition }\end{array}$ & $276 \sim 632^{\circ} \mathrm{C}$ \\
\hline
\end{tabular}
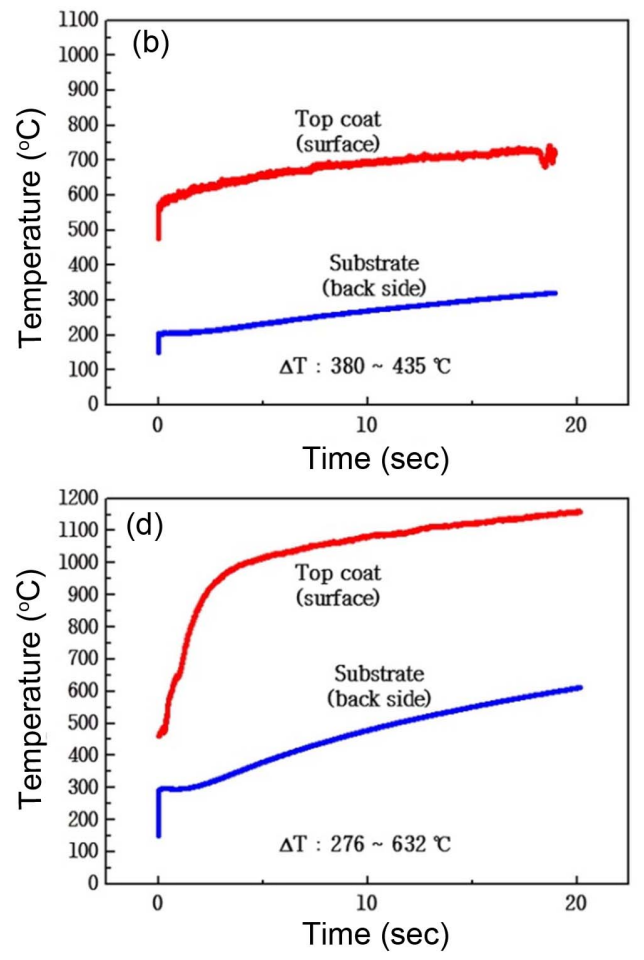

Fig. 9. Temperature differences of layered TBCs prepared with low thermal conductivity feedstock powder: (a) TBC system with buffer layer of regular purity and Co-Ni-based bond coat, (b) TBC system with buffer layer of high purity and Co-Nibased bond coat, (c) TBC system with buffer layer of regular purity and Ni-based bond coat, and (d) TBC system with buffer layer of high purity and Ni-based bond coat. 
be affirmed through application of low thermal conductivity materials and incorporation of the buffer layer which was similar to the case where the thickness of coating layer was increased to $850 \mu \mathrm{m}$. Also, the improvement in thermal barrier performance as a result of applying high-purity starting powder in the buffer layer may be considered to be a result of delaying extinction of pores with excellent sintering resistance under high-temperature environments. For the TBC system with the Co-Ni-based bond coat, delamination occurred at 720 cycles in the case where the buffer layer of general purity was incorporated, and at 218 cycles in the case where the buffer layer of high purity was incorporated. Meanwhile, for the TBC system with the Ni-based bond coat, delamination occurred at 1127 cycles in the case where the buffer layer of general purity was incorporated, whereas no delamination or fracture was observed up to 2000 cycles when the buffer layer of high purity was incorporated. Consequently, the improved thermal barrier performance and thermal durability could be secured together upon applica-
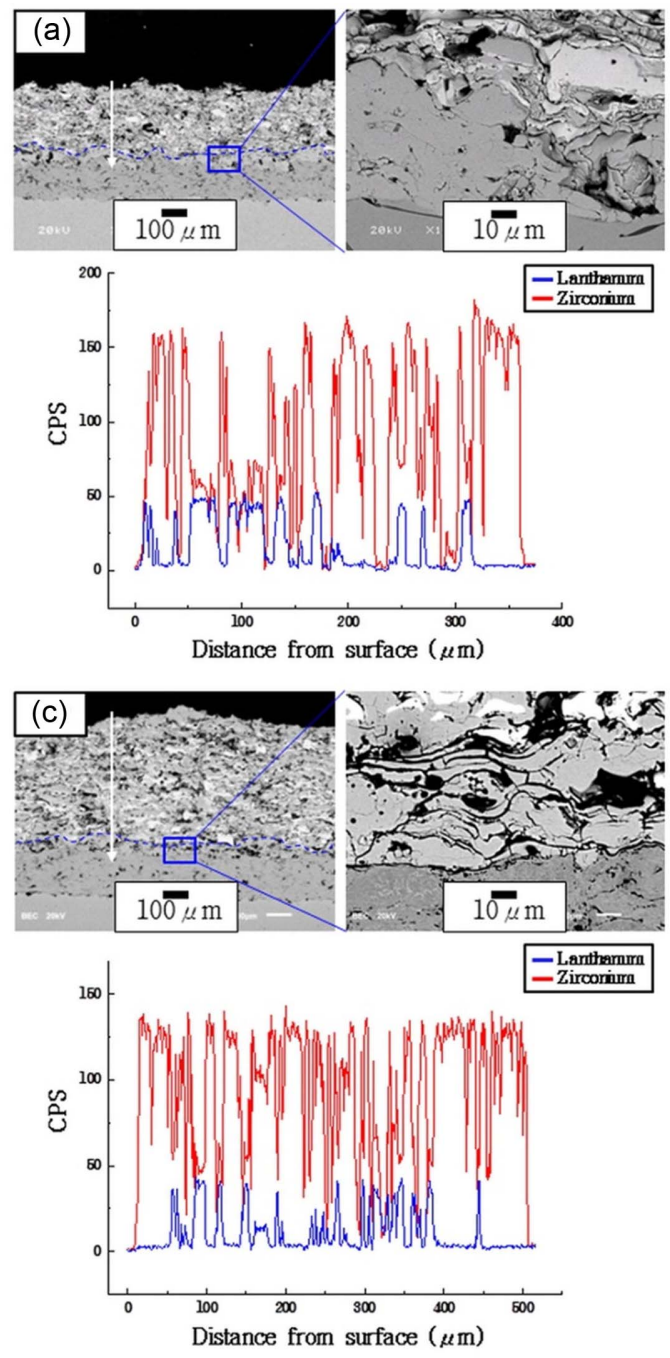

tion of the Ni-based bond coat as well as incorporation of the high-purity buffer layer in design and formation of TBC system.

\subsection{Thermal barrier performance in composition control for low thermal conductivity material and conversion to multilayer}

The cross-sectional microstructures of TBC systems formed in accordance with Fig. 3 are shown in Fig. 10, which was designed with variation in the composition and number of the buffer layer and in the composition and number of the top coat. The thicknesses of top coat, buffer layer, and bond coat were formed in accordance with the design concept. In the case of Fig. 10(a), the thicknesses of top coat, buffer layer, and bond coat were formed to be $244 \sim 294,28 \sim 70$, and $115 \sim 159 \mu \mathrm{m}$, respectively, while the thicknesses of top coat, buffer layer, and bond coat in Fig. 10(b) were formed to be $306 \sim 328,54 \sim 92$, and $135 \sim 173 \mu \mathrm{m}$, respectively. Meanwhile, the thickness of
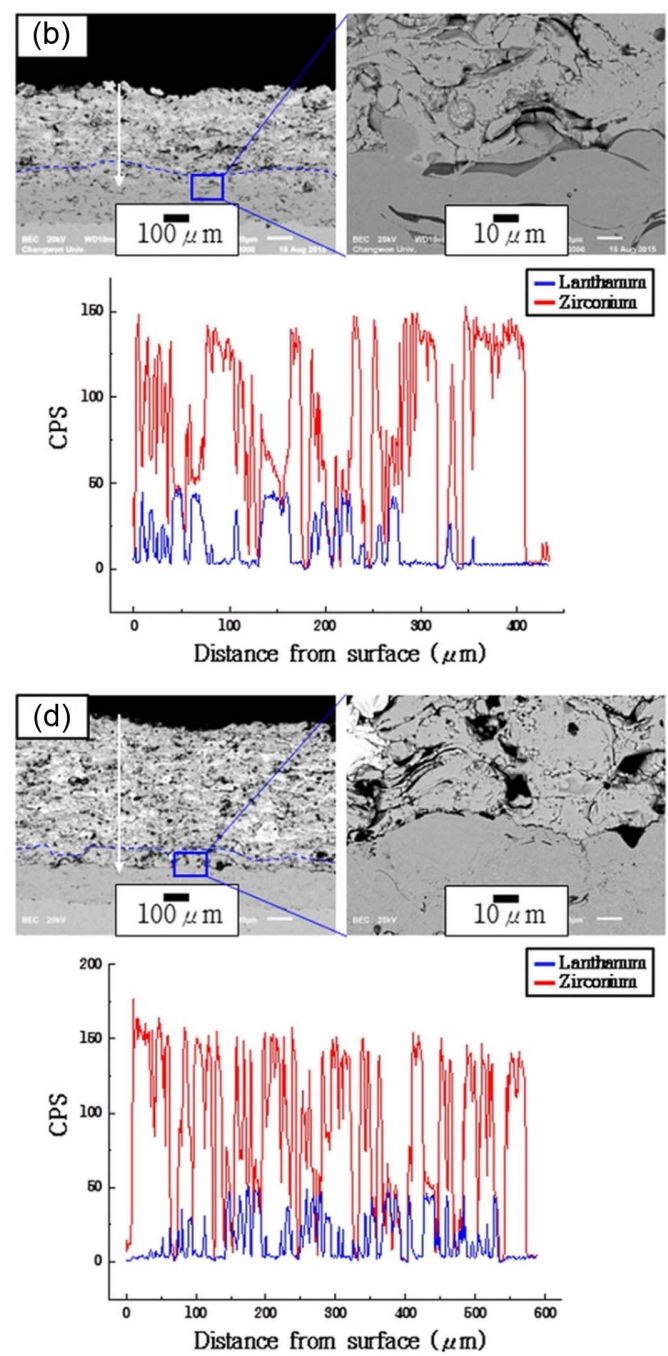

Fig. 10. Cross-sectional microstructures of as-coated TBCs prepared with the structural design shown in Fig. 3. Elemental analysis results for each cross-sectional microstructure and high magnified microstructures at the interfaces are shown in each figure. 
the buffer layer with mixed composition in Fig. 10(b) was calculated as a top coat layer. The thicknesses of the top coats in Figs. 10(c) and (d) were formed to be $437 \sim 517$ and $495 \sim 555 \mu \mathrm{m}$, the buffer layer $37 \sim 87$ and $38 \sim 64 \mu \mathrm{m}$, and the bond coat $161 \sim 175$ and $145 \sim 163 \mu \mathrm{m}$, respectively. Also, the thickness of the buffer layer with mixed composition in Fig. 10(d) was calculated as a top coat layer. In the surfaces of top coat, the microstructure of mixed composition of LZO and YSZ (Figs. 10(a) and 10(b)) and the microstructure of YSZ alone (Figs. 10(c) and 10(d)) can be detected, respectively. The interfaces of the first buffer layer (porous 8YSZ layer) and the second layer (top coat layer or the second buffer layer) are shown by dotted lines. Continuous microstructures were observed without differentiation of interfaces within the buffer layer and the top coat showing gradient composition. Meanwhile, incorporation of the YSZ buffer layer and the mixed layer (mixed layer of YSZ and LZO) was aimed at relaxation of a difference CTE from that of the bond coat which could occur when the low thermal conductivity material, LZO, was applied along with supplementation of low mechanical characteristics. Since the brighter colors could be observed to be displayed in the microstructures of the top coat and buffer layer as the added amount of the LZO was increased, proper formation of microstructures according to the design concept could be verified.

Temperature differences were measured for the case with incorporation of compositional continuity to control the thermal and residual stresses generated at the interfaces
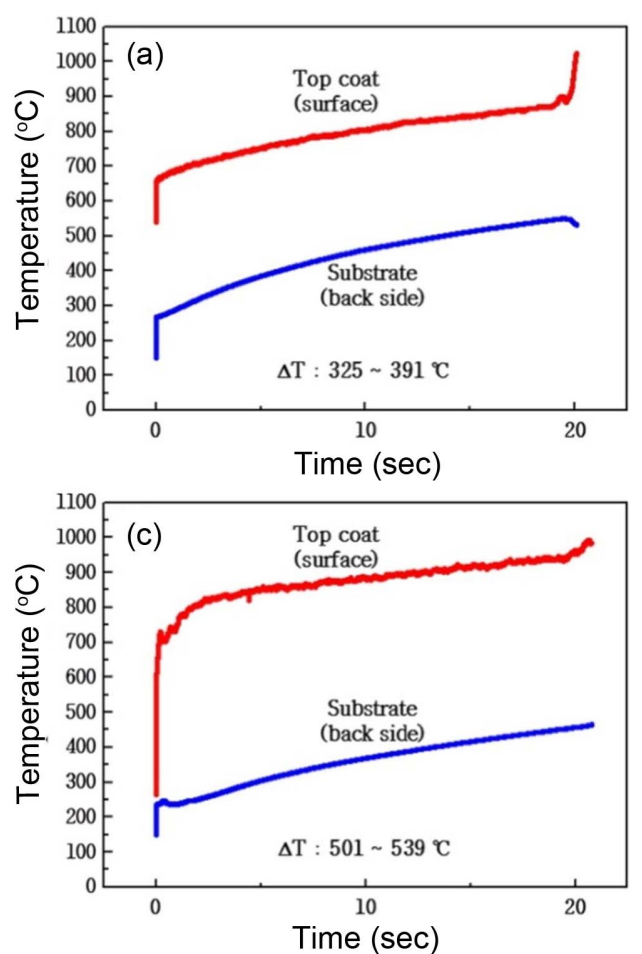

due to low CTE of low thermal conductivity materials, and for the multilayer structure aimed at performance improvement of surfaces, with the results shown in Table 3 and Fig. 11. Figs. 11(a) and 11(b) are the results of temperature difference measured in Section 3 (1000 1500 cycles), and Figs. 11(c) and 11(d) are the results of temperature difference measured in Section 1 ( $0 \sim 500$ cycles).

When the specimens in Fig. 11 had 2 layers (Fig. 11(a)), 3 layers (Fig. 11(b)), and 4 layers (Fig. 11(c)) as the top coat layers, a sound state was maintained up to 2000 cycles, while delamination occurred at 102 cycles in the case of 5 layers (Fig. 11(d)). First, when only the buffer layer of 8YSZ was incorporated (Figs. 11(a) and 11(c)), temperature differences were measured to be $325 \sim 391^{\circ} \mathrm{C}$ for the top coat $(2$

Table 3. Summary of the Numbers of Cycle-to-failure and its Status after JETS Tests for TBCs with Low Thermal Conductivity Material and Multilayer, as Shown in Fig. 3

\begin{tabular}{ccc}
\hline Type & Cycle & $\begin{array}{c}\text { Thermal barrier } \\
\text { performance }\end{array}$ \\
\hline Specimen a & $\begin{array}{c}2000 \text { cycles } \\
\text { Sound condition }\end{array}$ & $325 \sim 391^{\circ} \mathrm{C}$ \\
\hline Specimen b & $\begin{array}{c}2000 \text { cycles } \\
\text { Sound condition }\end{array}$ & $427 \sim 447^{\circ} \mathrm{C}$ \\
\hline Specimen c & $\begin{array}{c}2000 \text { cycles } \\
\text { Sound condition }\end{array}$ & $501 \sim 539^{\circ} \mathrm{C}$ \\
\hline Specimen d & $\begin{array}{c}102 \text { cycles } \\
\text { Delamination }\end{array}$ & $572 \sim 631^{\circ} \mathrm{C}$ \\
\hline
\end{tabular}
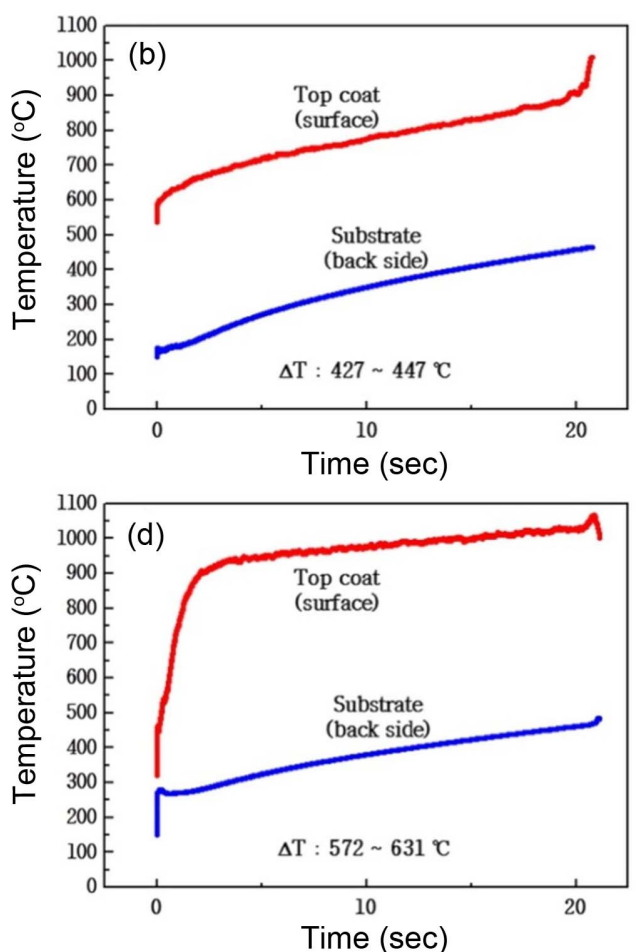

Fig. 11. Temperature differences of layered TBCs prepared with 8YSZ, blended feedstock powder, Ni-based bond coat: (a) TBC designed with Fig. 3(a), (b) TBC designed with Fig. 3(b), (c) TBC designed with Fig. 3(c), and (d) TBC designed with Fig. 3(d). 
layers, Fig. 11(a)) with LZO and YSZ being mixed in $50: 50$ vol\%, and $501 \sim 539^{\circ} \mathrm{C}$ for the multilayer top coat (4 layers, Fig. 11(c)). Consequently, improvement of thermal barrier performance could be affirmed when the number of interfaces between coating layers (number of layers) was increased in the multilayered structure. Namely, it is considered to be the scattering effect upon thermal diffusion at interfaces resulting from an increase in the number of interfaces and the result caused by a relatively thick coating thickness. Meanwhile, in the case of TBC system with the multilayered buffer layers (Figs. 11(b) and 11(d)), the temperature differences were shown to be $427 \sim 447^{\circ} \mathrm{C}$ for the top coat (3 layers, Fig. 11(b)) with LZO and YSZ being mixed in $50: 50 \mathrm{vol} \%$, and $572 \sim 631^{\circ} \mathrm{C}$ for the multilayer top coat (5 layers, Fig. 11(d)).

Although the low thermal conductivities of top coat and the thermal barrier performance at the multilayered structure were to be comparatively considered by making the thicknesses of Figs. 3(a) and 3(b) to be the same, and the thicknesses of Figs. 3(c) and 3(d) similar in the design concept for TBC systems, the specimen b (Fig. 10(b)) was formed to be thicker than the specimen a (Fig. 10(a)) in the actually formed TBCs. Therefore, the thickness of coating layer together with the previously mentioned scattering effect at interfaces is considered to have effects as the factors determining thermal barrier performance. Meanwhile, when a thickness similar to that of design concept was formed, a larger temperature difference was measured for the specimen $d$ (Fig. 10(d)) than the specimen c (Fig. 10(c)) of TBC systems having the multilayered structure at the interface. Based on this observation, an increase in the number of interfaces, i.e. the scattering effect at interfaces could be more efficient in improving thermal barrier performance. However, although an increase in the number of top coat layer, i.e. the number of interfaces in TBC system can produce improvement of thermal barrier performance, it is not considered to be desirable from the aspect of thermal durability, in view of the artificial defects which can be included in the forming process, resulting in the requirement for additional process control to secure interface stability. ${ }^{27)}$ Meanwhile, the thermal barrier performance evaluated in the present study showed larger temperature differences than the existing report where the TBCs with a thickness of about $100 \sim 500 \mu \mathrm{m}$ generally exhibited the thermal barrier performance of about $100 \sim 300^{\circ} \mathrm{C},{ }^{9)}$ because the metal substrate was cooled by the air at $400 \sim 600^{\circ} \mathrm{C}$ through cooling flow path under the environments where actual high-temperature components were applied. Consequently, although temperature difference in the present study may not be considered as the absolute thermal barrier performance for TBC systems, it could be utilized as a useful method for comparison of relative thermal barrier performance in developing and applying new materials, including structures.

TBCs with the single-layer buffer layer (Fig. 10(a)) and the bi-layer buffer layer (Fig. 10(b)) were completed up to
2000 cycles. While tests were conducted through 2000 cycles in Fig. 10(c) designed as a multilayered structure, delamination occurred at 102 cycles in Fig. 10(d). Consequently, quick delamination could be affirmed to occur upon incorporation of a large number of buffer layers in design and formation of TBC systems due to the defects between interfaces.

\section{Conclusions}

In the present study, surface temperatures of ceramic top coat and back face temperatures of substrate were measured during JETS tests as functions of thickness, composition, structure, and conversion to multilayer in TBC system to evaluate thermal barrier performance, and the following conclusions have been obtained.

1) As the thickness of TBC was increased, thermal barrier performance was improved, which was also affirmed in the relatively thin TBCs. As the thermal barrier performance was also improved by the same ratio when the thickness of TBC was increased by about 4 times $(850 \mathrm{~mm})$, the thermal barrier performance could be seen to have a proportional correlation up to a given thickness.

2) As a result of simultaneous application of the low thermal conductivity material of Yb-Gd-YSZ and the buffer layer in the TBC system, thermal barrier performance manifested upon an increase in the thickness of top coat in TBC systems could be secured, which is considered to be a result originating from the low thermal conductivity of top coat material and the scattering effect at the interfaces. Also, since the purity of starting material forming the buffer layer could provide sintering resistance under the repeated thermal shock environment, relatively excellent thermal barrier performance could be manifested.

3) In the TBCs with simultaneous application of the coating layer mixed with $\mathrm{La}_{2} \mathrm{Zr}_{2} \mathrm{O}_{7}$ and YSZ along and the buffer layer, thermal barrier performance was improved as a result of an increase in the number of buffer layers, which is considered to be a result originating from thermal scattering caused by an increased number of interfaces. In a comparison for the effects of application of the low thermal conductivity materials, an increase in thickness, and an increase in the number of interfaces which affect thermal barrier performance, the thermal barrier efficiency could be seen to be improved in the order of an increase in the number of interfaces, an increase in thickness, and application of the low thermal conductivity materials.

4) Whereas incorporation of the buffer layers for application of the low thermal conductivity materials is efficient for manifestation of thermal barrier performance on the basis of an increase in the number of interfaces and material characteristics, the increase in the number of interfaces also brings about an increase in artificial defects which can be included in the manufacturing process of TBC systems along with discontinuity at interfaces, etc. so as to reduce thermal durability. Consequently, additional process con- 
trol to secure interface stability and structural design considering thermal durability together will be required for application of the multilayered TBC system with a low thermal conductivity material.

\section{Acknowledgments}

This work was supported by a National Research Foundation of Korea (NRF) grant funded by the Korean Government (grant number 2011-0030058) and the Ministry of Science, ICT and Future Planning (grant number 2344413.C).

\section{REFERENCES}

1. D. R. Clarke and S. R. Phillpot, "Thermal Barrier Coating Materials," Mater. Today, 8 [6] 22-9 (2005)

2. R. Vaßen, M. O. Jarligo, T. Steinke, D. E. Mack, and D. Stöver, "Overview on Advanced Thermal Barrier Coatings," Surf. Coat. Technol., 205 [4] 938-42 (2010).

3. M. Gell, E. Jordan, K. Vaidyanathan, K. McCarron, B. Barber, Y. H. Sohn, and V. K. Tolpygo, "Bond Strength, Bond Stress and Spallation Mechanisms of Thermal Barrier Coatings," Surf. Coat. Technol., 120 [121] 53-60 (1999).

4. H. Herman, S. Sampath, and R. McCune, "Thermal Spray: Current Status and Future Trends," MRS Bull., 25 [07] 1725 (2000)

5. U. Schulz, C. Leyens, K. Fritscher, M. Peters, S. B. Bilge, O. Lavigne, J. M. Dorvaux, M. Poulain, R. Mévrel, and M. Caliez, "Some Recent Trends in Research and Technologyof Advanced Thermal Barrier Coatings," Aero. Sci. Technol., 7 [1] 73-80 (2003).

6. T. S. Sidhu, S. Prakash, and R. D. Agrawal, "Studies on the Properties of High-Velocity Oxy-Fuel Thermal Spray Coatings for Higher Temperature Applications," Surf. Coat. Technol., 41 [6] 805-23 (2009).

7. X. Q. Cao, R. Vaßen, and D. Stöver, "Ceramic Materials for Thermal Barrier Coatings,” J. Eur. Ceram. Soc., 24 [1] 1-10 (2004).

8. W. A. Nelson and R. M. Orenstein, "TBC Experience in Land-Based Gas Turbines," J. Therm. Spray Technol., 6 [2] 176-80 (1997).

9. R. L. Jones, Metallurgical and Ceramic Protective Coatings: Thermal Barrier Coatings; pp. 194-235, Chapman and Hall, London, 1996.

10. S. Paul, A. Cipitria, S. A. Tsipas, and T. W. Clyne, "Sintering Characteristics of Plasma Sprayed Zirconia Coatings Containing Different Stabilizers," Surf. Coat. Technol., 203 [8] 1069-74 (2009).

11. A. G. Ebans, D. R. Mumm, J. W. Hutchinson, G. H. Meier, and F. S. Pettit, "Mechanisms Controlling the Durability of Thermal Barrier Coatings," Prog. Mater. Sci., 46 [5] 505-53 (2001).

12. D. R. Clarke, M. Oechsner, and N. P. Padture, "ThermalBarrier Coatings for More Efficient Gas-Turbine Engines,"
MRS Bull., 37 [10] 891-98 (2012).

13. D. R. Clarke and C. G. Levi, "Materials Design for the Next Generation Thermal Barrier Coatings," Annu. Rev. Mater. Res., 33 [1] 383-417 (2003).

14. R. A. Miller, "Current Status of Thermal Barrier Coatings an Overview," Surf. Coat. Technol., 30 [1] 1-11 (1987).

15. C. G. Levi, "Emerging Materials and Processes for Thermal Barrier Systems," Curr. Opin. Solid State Mater. Sci., 8 [1] 77-91 (2004).

16. L. Guo, H. Guo, H. Peng, and S. Gong, "Thermophysical Properties of $\mathrm{Yb}_{2} \mathrm{O}_{3}$ doped $\mathrm{Gd}_{2} \mathrm{Zr}_{2} \mathrm{O}_{7}$ and Thermal Cycling Durability of $\left(\mathrm{Gd}_{0.9} \mathrm{Yb}_{0.1}\right)_{2} \mathrm{Zr}_{2} \mathrm{O}_{7} / \mathrm{YSZ}$ Thermal Barrier Coatings," J. Eur. Ceram. Soc., 34 [5] 1255-63 (2014).

17. E. Bakan, D. E. Mack, G. Mauer, and R. Vaßen, "Gadolinium Zirconate/YSZ Thermal Barrier Coatings: Plasma Spraying, Microstructure, and Thermal Cycling Behavior," J. Am. Ceram. Soc., 97 [12] 4045-51 (2014).

18. R. Vassen, X. Cao, F. Tietz, D. Basu, and D. Stover, "Zirconates as New Materials for Thermal Barrier Coatings," J. Am. Ceram. Soc., 83 [8] 2023-28 (2000).

19. T. A. Taylor, "Low Thermal Expansion BondCoats for Thermal Barrier Coatings," US Patent, 7,910,225, (March 22, 2011).

20. G. Dwivedi, V. Viswanathan, S. Sampath, A. Shyam, and L. C. Edgar, "Fracture Toughness of Plasma-Sprayed Thermal Barrier Ceramics: Influence of Processing, Microstructure, and Thermal Aging," J. Am. Ceram. Soc., 9 [9] 273644 (2014).

21. J. M. Drexler, C. H. Chen, A. D. Gledhill, K. Shinoda, S. Sampath, and N. P. Padture, "Plasma Sprayed Gadolinium Zirconate Thermal Barrier Coatings that are Resistant to Damage by Molten Ca-Mg-Al-Silicate Glass," Surf. Coat. Technol., 206 [19-20] 3911-16 (2012).

22. R. Vaßen, F. Traeger, and D. Stöver, "New Thermal Barrier Coatings Based on Pyrochlore/YSZ/ Double-Layer Systems," Inter. J. App. Ceram. Technol., 1 [4] 351-61 (2004).

23. L. Wang, Y. Wang, X. G. Sun, J.Q. He, Z. Y. Pan, and C. H. Wang, "Thermal Shock Behavior of 8YSZ and DoubleCeramic-Layer $\mathrm{La}_{2} \mathrm{Zr}_{2} \mathrm{O}_{7} / 8 \mathrm{YSZ}$ Thermal Barrier Coatings Fabricated by Atmospheric Plasma Spraying," Ceram. Inter., 38 [5] 3595-606 (2012).

24. P. W. Scholke, "Advanced Gas Turbine Materials and Coatings", (GE Energy, Schenectady, NY, 1991).

25. V. Viswanathan, G. Dwivedi, and S. Sampath, "Engineered Multilayer Thermal Barrier Coatings for Enhanced Durability and Functional Performance," J. Am. Ceram. Soc., 97 [9] 2770-78 (2014).

26. A. N. Khan and J. Lu, "Behavior of Air Plasma Sprayed Thermal Barrier Coatings, Subject to Intense Thermal Cycling," Surf. Coat. Technol., 166 [1] 37-43 (2003).

27. K. Bobzin, N. Bagcivan, T. Brögelmann, and B. Yildirim, "Influence of Temperature on Phase Stability and Thermal Conductivity of Single and Double-Ceramic-Layer EBPVD TBC Top Coats Consisting of $7 \mathrm{YSZ}, \mathrm{Gd}_{2} \mathrm{Zr}_{2} \mathrm{O}_{7}$ and $\mathrm{La}_{2} \mathrm{Zr}_{2} \mathrm{O}_{7}$," Surf. Coat. Technol., 237 56-64 (2013). 